\title{
LUMPY SKIN DISEASE: AN EMERGING BOVINE VIRAL INFECTION IN INDIA
}

\author{
N. AHMED ${ }^{1 *}$, S. DOLEY' ${ }^{2}$, S. A. BARLASKAR ${ }^{3}$, \\ A. J. NATH ${ }^{1}$ AND S. N. YADAV ${ }^{1}$ \\ ${ }^{1}$ Lakhimpur College of Veterinary Science, Assam Agricultural University, North Lakhimpur -787 \\ 051, Assam, India \\ ${ }^{2}$ State Veterinary Dispensary, Mathurapur, Animal Husbandry and Veterinary Department, Charaideo \\ - 785 689, Assam, India \\ ${ }^{3}$ The West Assam Milk Producers' Co-operative Union Limited, Assam Agribusiness and Rural \\ Transformation Project (APART), Guwahati - 781 037, Assam India

\begin{abstract}
Lumpy skin disease (LSD) is a highly infectious emerging viral disease of cattle and buffaloes in India. The main source of transmission of the disease is arthropods (mosquitoes, biting flies, Culicoides midges and three blood sucking hard ticks) which act as mechanical vector. Major clinical signs include skin nodules all over the body, fever, lacrimal discharge, nasal discharge, anorexia, decreased milk yield, emaciation, depression and reluctance in movement. Since the first report of lumpy skin disease in India, it is spreading rapidly across the country causing a possible threat to the cattle and buffalo population in terms of productivity and mortality.
\end{abstract}

Key words: Emerging, India, Lumpy skin disease, Productivity

\section{Introduction}

Lumpy skin disease (LSD) is an important infectious transboundary infection of cattle and buffaloes of all age groups and breeds. This is an emerging viral infection having important economic significance across the world. LSD is also called as neethling virus disease, pseudo urticaria, exanthema nodularis bovis and Knopvelsiekte causing temporary to permanent damage to the skin characterized by distinctive nodular lesions leading to detrimental effect on the commercial value of hides (Amenu et al., 2018; Feyisa, 2018). Moreover, LSD causes severe loss to the farmers in terms of chronic debility, decreased milk yield, poor growth rate, infertility, abortion and even death (Babiuk et al., 2008; Abutarbush et al., 2013). As per $20^{\text {th }}$ Livestock Census, the total cattle and buffalo population of India is 192.49 and 109.85 million respectively. Most of the Indian population is directly involved in dairy industry. Recently, lumpy skin disease has been reported in India and is spreading rapidly across the country which may indirectly correlate the productivity due to stress by associated viral infection. In this context, the present article describes the details of LSD along with possible way of prevention and control measures to overcome the production loss.

\section{History of outbreaks}

Lumpy skin disease (LSD) had been reported for the first time in North Rhodesia (Zambia) in the year 1929, which was initially thought to be due to an allergic reaction in cattle caused

*Corresponding Author 
by biting insects (MacDonald, 1931). Similar clinical signs were recognized in Botswana, Republic of South Africa and Zimbabwe in between 1943 and 1945 (Al-Salihi, 2014). In 1972, LSD was reported in Sudan (Ali and Obeid, 1977). It was transmitted to Somalia in 1983 (Davies, 1991). By the year 1974, the disease was spread to west as far as Nigeria and in 1977 it was transmitted to Mauritania, Mali, Ghana and Liberia (OIE, 2010). LSD was restricted to countries in sub-Saharan Africa from 1929 to 1986 (Gumbe, 2018). Epidemic of lumpy skin disease outside the sub-Saharan African continent had reported in Egypt (1988), Israel (1989), Kuwait (1991), Lebanon (1993), Yemen (1995), United Arab Emirates (2000), Bahrain (2003), Israel (2006-2007) and Oman (2010) (Tageldin et al., 2014). In India, lumpy skin disease had been first reported from Mayurbhanj and Bhadrak Districts in Odisha in August, 2019 (Sudhakar et al., 2020).

\section{Causative agent and its properties}

Lumpy skin disease (LSD) is caused by lumpy skin disease virus which has epitheliotrophic property (Gari et al., 2010). It is a member of the genus Capripoxvirus of the family Poxviridae. Sheep pox and Goat pox are the two other virus species of genus Capripoxvirus. Genetically, LSD virus is very similar to the other Capripox species such as Sheep pox and Goat pox virus. The virus has a double-stranded DNA genome of about 151 kbp. It is enveloped, linear, ovoid shaped virion measuring 220-450 nanometer (nm) by $140-266$ nm (Stram et al., 2008).

Lumpy skin disease (LSD) virus is susceptible to temperature $\left(55^{\circ} \mathrm{C}\right.$ for 2 hours; $65^{\circ} \mathrm{C}$ for 30 minutes) and detergents containing lipid solvents like ether $(20 \%)$, chloroform, formalin $(1 \%)$, phenol $(2 \%)$, sodium hypochlorite (2$3 \%)$, iodine compound ( $1: 33$ dilution) and quaternary ammonium compounds $(0.5 \%)$. However, the virus can withstand drying, $\mathrm{pH}$ shift (if not an extreme $\mathrm{pH}$ ) and can remain viable for months in dark room such as infected animal shades. It can persist in skin plugs for about 42 days (Abeya et al., 2018). The virus can be isolated from the nodules kept at $-80^{\circ} \mathrm{C}$ for 10 years and infected tissue culture fluid stored at $4^{\circ} \mathrm{C}$ for 6 months.

\section{Host range}

Lumpy skin disease (LSD) virus has narrow and specific host range. It does not have any non ruminant host (Shen et al., 2011). It causes natural infection in cattle (Bos indicus and Bos taurus) and Asian water buffaloes (Bubalus bubalis) (Ali et al., 1990; Tuppurainen et al., 2017). However, susceptibility rate is significantly higher in cattle $(30.8 \%)$ than buffaloes (1.6\%) (El-Nahas et al., 2011). All cattle appear to be equally susceptible to the disease irrespective of breeds (Al-Salihi, 2014). However, some researchers have reported that Bos taurus is more prone to LSD than Bos indicus which might be due to exotic breeds are less resistant against diseases. Coetzer (2004) had observed that the losses were more in severe cases of the disease in Bos taurus or imported breeds with relatively thin skin than Bos indicus or indigenous breeds with thicker skin diameter. Cattle of both sexes and all age groups are susceptible to the infection, however there is evidence that young animal may be more susceptible to the severe form of the infection (Al-Salihi, 2014). The disease had been demonstrated after experimental infection in impala, giraffe and Thomsons gazelle (Young et al., 1968). It had also been reported in an Arabian oryx and springbok (Greth et al., 1992; Tuppurainen et al., 2017).

\section{Transmission}

The principal way of transmission of LSD virus is arthropods which act as mechanical vector. Albeit rare transmission occurs through direct contact and contaminated feed and water (Ali et al., 2012). Incidence is more prevalent in low lying agro-climate zone and along water courses 
during the wet and warmer condition of summer and autumn months, which favours arthropod multiplication (OIE, 2010). The mosquitoes (Culex mirificens and Aedes aegypti), biting flies (Stomoxys calcitrans and Biomyia fasciata), Culicoides midges and three blood sucking hard ticks viz. Rhipicephalus (Boophilus) decoloratus (blue tick), Rhipicephalus appendiculatus (brown ear tick) and Amblyomma hebraeum are identified as vector as well as act as reservoir of the virus (Sarma, 2009; Lubinga et al., 2014). The virus is present in all secretions of the infected animals such as blood, saliva, semen, nasal discharge, lachrymal discharge and milk, and cutaneous lesions (Babiuk et al., 2008). Moreover, infected pregnant cows are known to deliver calves with skin lesions (Tuppurainen et al., 2017).

\section{Pathogenesis}

Lumpy skin disease (LSD) virus enters the host body through skin or gastro intestinal tract mucosa resulting in viraemia accompanied by febrile reactions which persist for two weeks. The virus reaches the regional lymph nodes and causes lymphadenitis. The virus causes skin lesions due to its rapid replication in specific cells such as endothelial cells of lymphatic and blood vessel walls with development of inflammatory nodules on the skin (Vorster and Mapham, 2008). The disease is a generalized epitheliotrophic disease causing localized and systemic reaction resulting vasculitis and lymphadenitis that result to edema and necrosis. In some severe cases, thrombosis and infarction may be observed. Skin nodules may be changed to grey-pink with caseous necrotic cores. Circumscribed necrotic lesions may ulcerate referred as 'sit-fasts'. Lymph nodes are enlarged and secondary bacterial infections are common in the necrotic cores. Multiple virus-encoded factors are produced during infection, which influence pathogenesis and disease (Tuppurainen et al., 2017).

\section{Clinical signs}

Lumpy skin disease (LSD) can occur in acute, sub acute and chronic forms (Gari et al., 2010). The incubation period of the disease varies from 4 to 14 days in experimental conditions whereas in natural infection, the incubation period is 2 to 5 weeks (Carn and Kitching, 1995; Tuppuraine et al., 2005). The different clinical signs visible in the disease are skin nodules all over the body, fever (may exceeds $41^{\circ} \mathrm{C}$ ) which persists for 6 to 72 hours, lacrimal discharge, nasal discharge, anorexia, decreased milk yield, emaciation, depression and reluctance in movement (Al-Salihi, 2014). Skin nodules (Fig. 1) can be observed over the muzzle, nares, back, limbs, scrotum, udder, perineum, eyelids, ears, nasal mucosa, oral mucosa and tail (Salib and Osman, 2011). Skin nodules may disappear, but sometimes these may persist as hard lumps or become moist, necrotic and ulcerated (Fig. 2). The ulcerated lesions may create a hole in the skin (Abutarbush et al., 2013). These ulcerated lesions may be contaminated by secondary bacterial complication and infestation of fly worms (Amenu et al., 2018). Tuppurainen et al., (2017) observed that subscapular and prefemoral lymph nodes had become enlarged to 3-5 times of their normal size and easily palpable (Fig. 3). Edematous and inflammatory swellings of the face, brisket and one or more limbs (Fig. 4, 5), may be seen leading to difficulties in movement. In some cases, unilateral or bilateral keratitis may be observed in infected animals (Jameel, 2016). Pneumonia is a common sequel in animals affected by LSD with lesions in the mouth and respiratory tract (Al-Salihi, 2014). Females infected with the disease may remain in anestrus for months or become sterile due to poor body condition and other stress (Al-Salihi, 2014). In some cases, the affected pregnant animals may abort. In infected bulls, there may be orchitis leading to infertility to sterility (Sarma, 2009). 
Indian Journal of Animal Health, December, 2020

\section{Lumpy skin disease: An emerging disease}
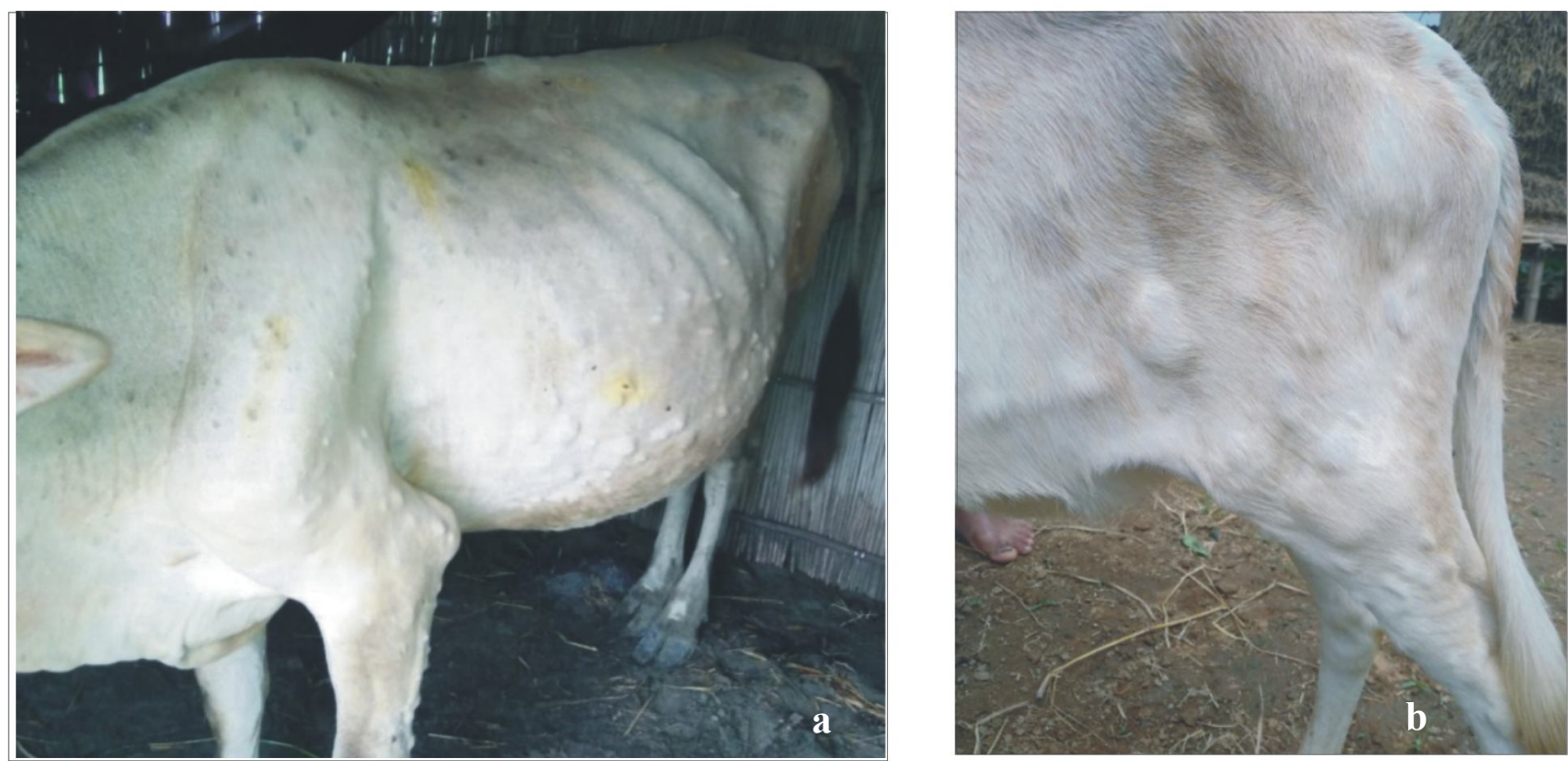

Fig. 1. Characteristic nodular skin lumps of lumpy skin disease (a, b)

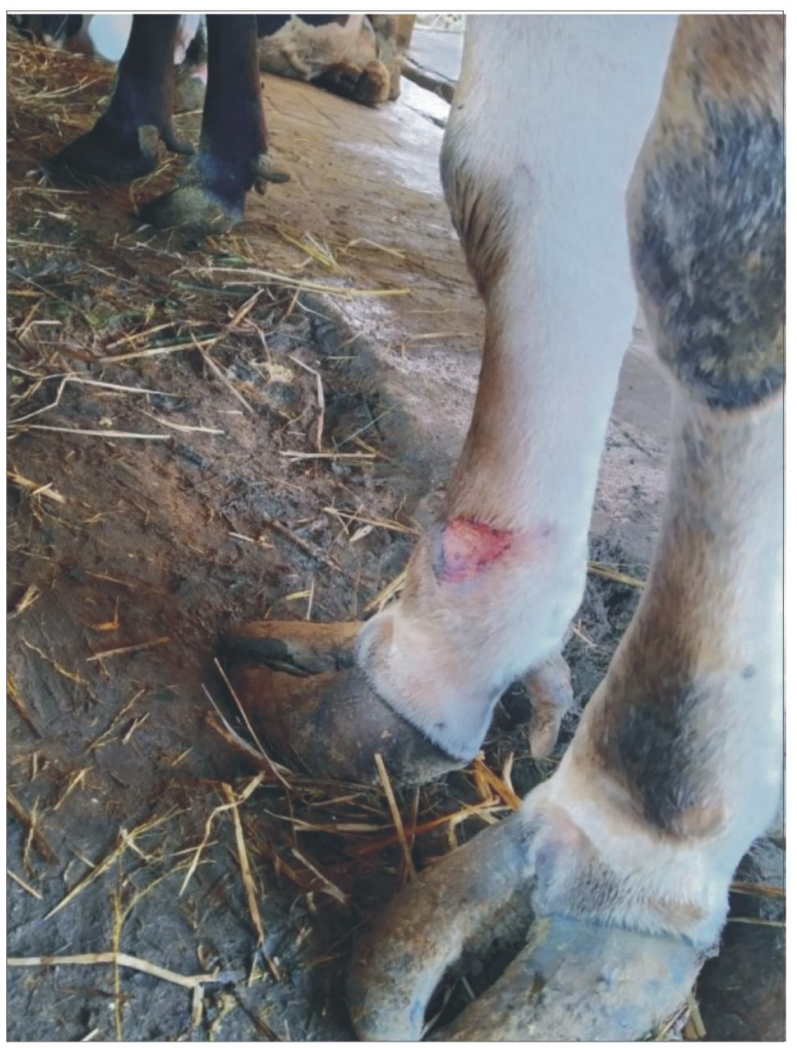

Fig. 2. Ulcerated skin lesion

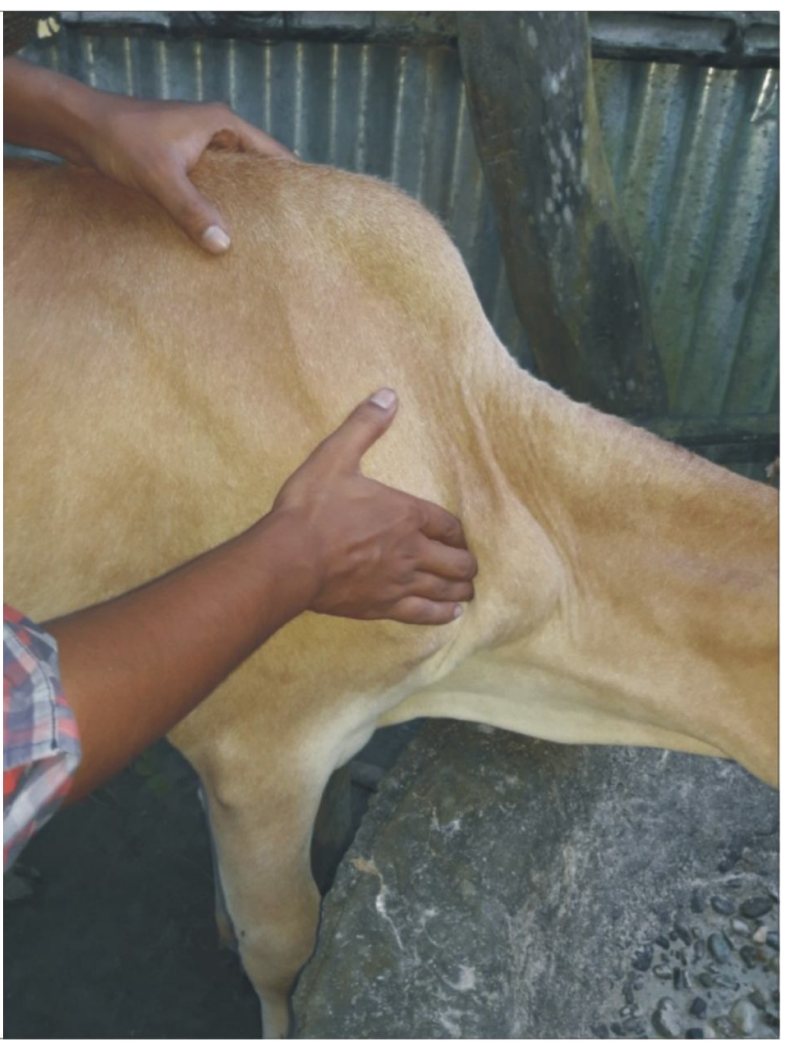

Fig. 3. Easily palpable enlarged subscapular lymph node 
Indian Journal of Animal Health, December, 2020

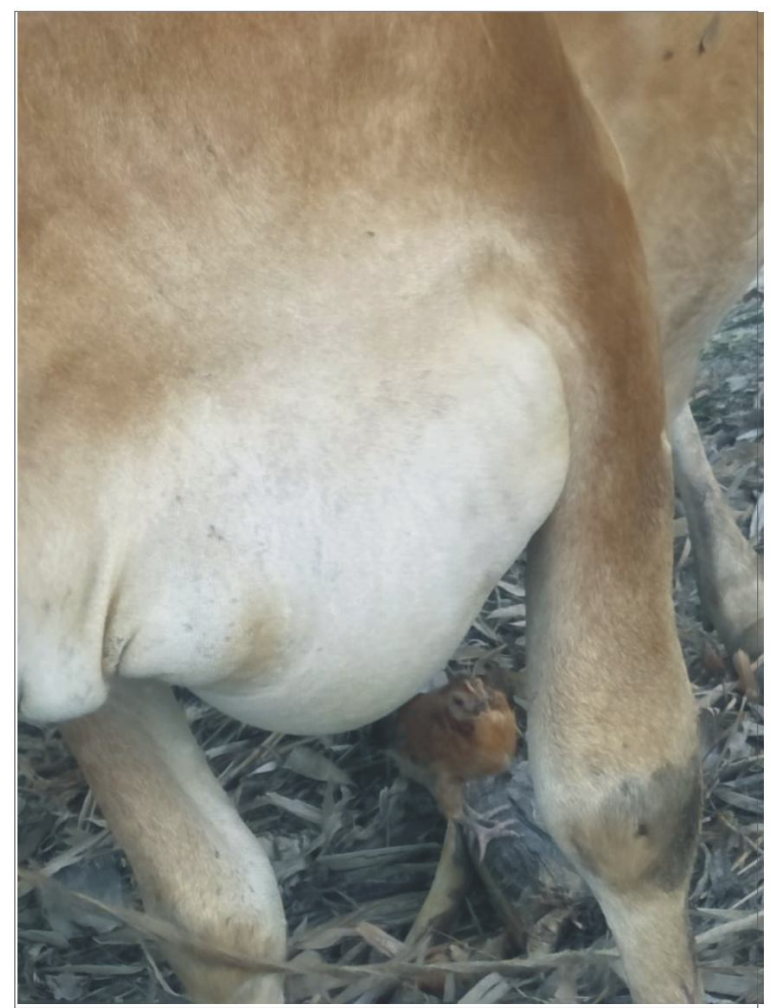

Fig. 4. Edematous swelling of brisket

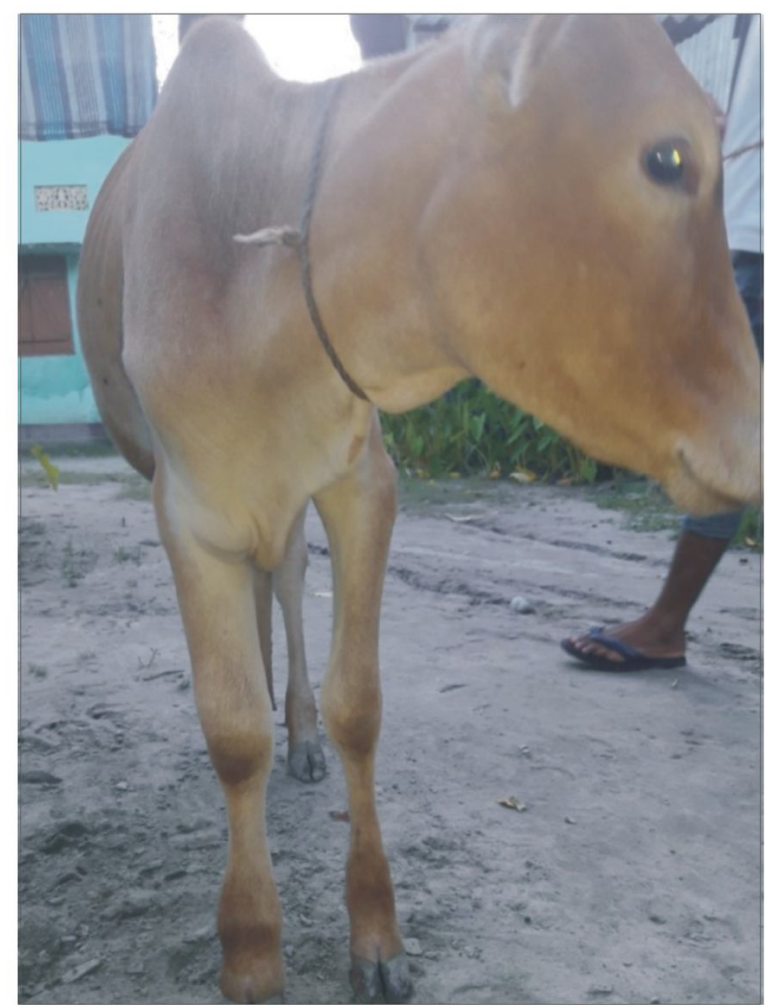

Fig. 5. Swelling of the right forelimb

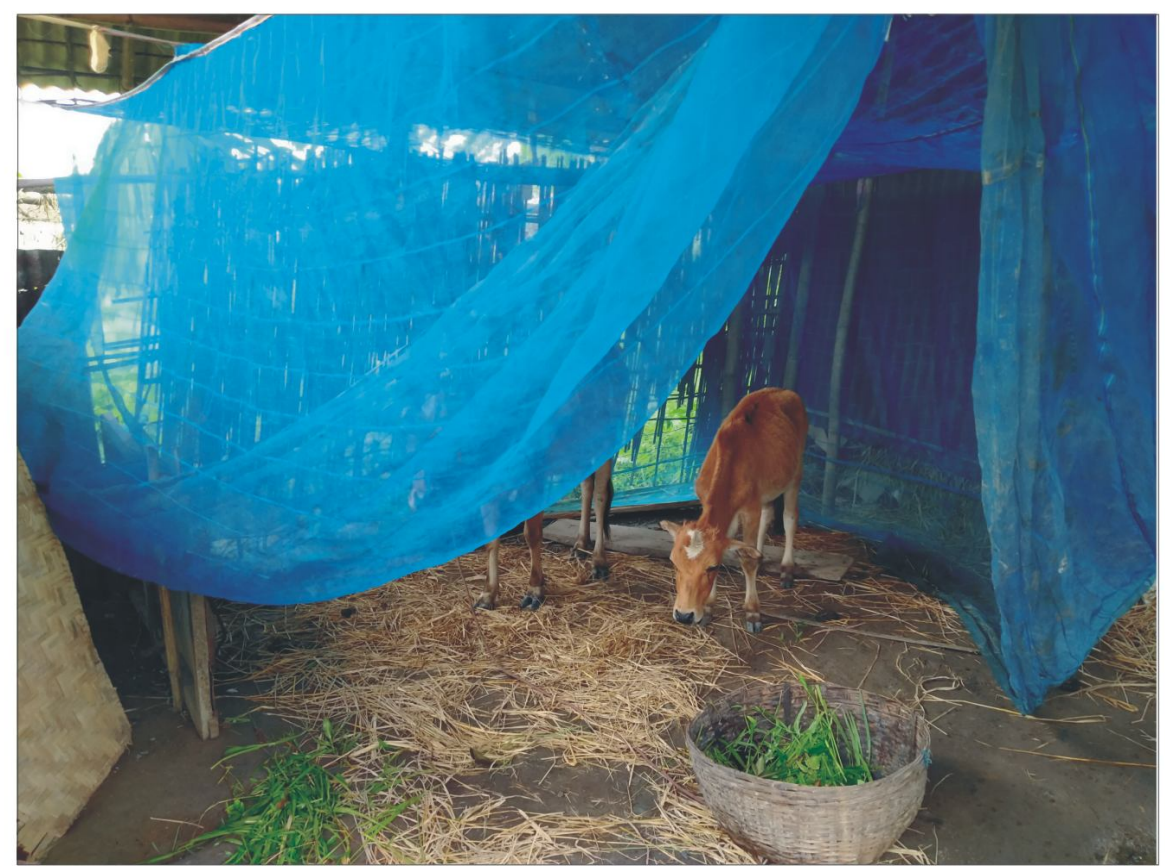

Fig. 6. Insect proof housing for cattle in endemic area 


\section{Morbidity and mortality}

The morbidity and mortality rates vary based on the status of the host's immune system and seasons due to abundance of arthropod vectors. Morbidity rate of the disease is highest in wet and warm weather and lowest during the dry season (OIE, 2008). Morbidity rate varies between $5-45$ percent and mortality rate is 1- 5 percent (Al-Salihi, 2014). However, in natural outbreaks, morbidity rate may reach as high as $100 \%$ and mortality rate may sometimes reach $40 \%$ (Amenu et al., 2018).

\section{Diagnosis}

Lumpy skin disease (LSD) can be diagnosed based on peculiar clinical signs of the disease and the incidence of disease outbreak in nearby areas. However confirmatory diagnosis is furnished by laboratory tests with the presence of viral antigen or antibody (Amenu et al., 2018). Non necrosed skin nodules biopsy samples or post mortem skin nodules, lung lesions and lymph nodes are collected within first week of onset of clinical sings of the disease before the development of neutralizing antibodies for isolation and identification of the viral antigen (Abeya et al., 2018). The viral antigen can also be isolated from buffy coat of the blood sample collected into EDTA or heparin during the viraemic stage of the disease (Al-Salihi, 2014). LSD virus grows slowly on cell cultures and may require several passages. They can be recognizable by cytopathic effects. The virus can propagate in the chorioallantoic membranes of embryonated chicken eggs and African green monkey kidney (Vero) cells, causing macroscopic pock lesions. The replication of the virus occurs in the cytoplasm of the host's cell resulting in intracytoplasmic eosinophilic inclusion bodies (Abeya et al., 2018).

Commonly used method of diagnosing LSD is detecting viral DNA using the polymerase chain reaction. Other laboratory tests carried out for diagnosis of LSD are electron microscopy, virus neutralization test, indirect fluorescence tests, agar gel immunodiffusion test, Western blot and enzyme-linked immunosorbent assay (OIE, 2016).

It is important to differentiate the LSD from other similar skin diseases viz. pseudo lumpy skin disease, pseudo cow pox, bovine papular stomatitis, insect bites, urticaria, photosensitization, dermatophilosis, demodicosis, besnoitiosis, ringworm etc. (Tuppurainen et al., 2017).

\section{Treatment}

As LSD is a viral disease, there is no specific treatment till date. However, the infected animals are treated with antibiotics to prevent other secondary bacterial invasion and other supportive medications to subside the clinical signs (Al-Salihi, 2014). Local dressing of the skin with antiseptic is also suggested to prevent flies and bacterial infection (Amenu et al., 2018). Antibiotics like penicillins, cephalosporins, tetracyclines, fluroquinolones etc. are indicated for 5 to 7 days depending on severity of the disease (Feyisa, 2018). Administration of antihistaminic and non steroidal anti-inflammatory drugs are also indicated. Antipyretic drug like paracetamol is given to subside the fever. To overcome the anorexia and speedy recovery liver supportive and multivitamins should be administered regularly.

\section{Prevention and control}

In endemic areas, isolation of the diseased animals are carried out to prevent spread of the disease into the healthy herd. Moreover, newly purchased animals must be quarantined before introduction to the healthy herd. Purchase of animals from the endemic areas should strictly be restricted. In addition, Abeya et al. (2018) had suggested that in newly spread areas the infected animals are to be slaughtered and 
properly disposed along with contacted equipments and premises must be thoroughly cleaned and disinfected. Control of insect vectors to minimize the spread of LSD by using insecticides, insect repellents and providing insect proof housing (Fig. 6) for animals (Babiuk et al., 2008) are recommended. In endemic areas, vaccination of the animals (above 6 months age) every year is the method of control of the disease. Four live attenuated strains of capripoxvirus are currently used as vaccines to control the lumpy skin disease outbreak viz. Kenyan sheep and goat pox strain (KS-1), Yugoslavian RM 65 sheep pox strain, Romanian sheep pox strain and South African

\section{REFERENCES}

Abeya A, Feyisa B, Gezali A and Derej A, 2018. Review on epidemiological aspects and economic impact of lumpy skin disease. J Dairy Vet Sci, 7(4): 555716, doi: 10.19080/ JDVS.2018.07.555716

Abutarbush SM, Ababneh MM, Al Zoubil IG, Al Sheyab OM, Al Zoubi MG et al., 2013. Lumpy skin disease in Jordan: disease emergence, clinical signs, complications and preliminary-associated economic losses. Transbound Emerg Dis, 62: 549-554, doi: 10.1111/tbed.12177. Epub 2013 Oct 21

Ali AA, Esmat M, Attia H, Selim A and AbdelHumid YM, 1990. Clinical and pathological studies on lumpy skin disease in Egypt. Vet Rec, 127(22): 549-550

Ali BH and Obeid HM, 1977. Investigation of the first outbreak of lumpy skin disease in the Sudan. Br Vet J, 133(2): 184-189, doi: 10.1016/s00071935(17)34140-4

Ali H, Ali AA, Atta MS and Cepica A, 2012. Common, emerging, vector - borne and abortogenic virus infections of cattle. Transbound Emerg Dis, 59(1): $11-25$, doi: $10.1111 / \mathrm{j} .1865-$ 1682.2011.01240.x

Al-Salihi KA, 2014. Lumpy skin disease: review of literature. Mirror Res Vet Sci Anim, 3(3): 6-23 neethling lumpy skin disease virus strain.

\section{Conclusion}

Lumpy skin disease (LSD) is a highly infectious viral disease of cattle and buffaloes. As the disease is newly reported in India, it becomes a serious threat to the entire bovine population in India. Though the mortality is less in LSD but negligence and lack of knowledge may cause great production loss or even death of the animals. Better understanding and awareness for LSD are of utmost necessity to tackle the production loss due the disease in India.

Conflict of interest: The authors declare that they have no competing interests.

Amenu A, Bekuma F, Abafaji G and Abera D, 2018. Review on epidemiological aspects and economic impact of lumpy skin disease. J Dairy Vet Sci, 7(4): 555716, doi: 10.19080/ JDVS.2018.07.555716

Babiuk S, Bowden TR, Boyle DB, Wallace DB and Kitching RP, 2008. Capripoxviruses: an emerging worldwide threat to sheep goats and cattle. Transbound Emerg Dis, 55(7): 263-272, doi: $10.1111 / \mathrm{j} .1865-1682.2008 .01043 . \mathrm{x}$

Carn VM and Kitching RP, 1995. The clinical response of cattle experimentally infected with lumpy skin disease (Neethling) virus. Arch Virol, 140: 503-513, doi: 10.1007/BF01718427

Coetzer JAW, 2004. Lumpy skin disease. In: Coetzer JAW, Tustin RC, editors. Infectious Diseases of Livestock. Oxford University Press

Davies FG, 1991. Lumpy skin disease, an African capripox virus disease of cattle. Br Vet J, 147(6): 489-503

El-Nahas EM, El-Habbaa AS, El-Bagoury GF and Radwan MEI, 2011. Isolation and identification of lumpy skin disease virus from naturally infected buffaloes at Kaluobia, Egypt. Glob Vet, 7(3): 234-237

Feyisa AF, 2018. A case report on clinical management 
of lumpy skin disease in bull. J Vet Sci Technol, 9(3): 538, doi: 10.4172/2157-7579.1000538

Gari G, Waret-Szkuta A, Grosbois V, Jacquiet P and Roger F, 2010. Risk factors associated with observed clinical lumpy skin disease in Ethiopia. Epidemiol Infect, 138(11): 16571666, doi: 10.1017/S0950268810000506

Greth A, Gourreau JM, Vassart M, Vy NB, Wyers M et al., 1992. Capripoxvirus disease in an Arabian Oryx (Oryx leucoryx) from Saudi Arabia. J Wildl Dis, 28(2): 295-300, doi: 10.7589/0090-3558-28.2.295

Gumbe AAF, 2018. Review on lumpy skin disease and its economic impacts in Ethiopia. J Dairy Vet Anim Res, 7(2): 39-46, doi: 10.15406/ jdvar.2018.07.00187

Jameel GH, 2016. Determination of complications decrease the risk factor in cattle infected by lumpy skin disease virus in Diyala province, Iraq. Int J Micro Biol Genet Monocu Biol Res, 2(1): $1-9$

Lubinga JC, Clift SJ, Tuppurainen ESM, Stoltsz WH, Babiuk S et al., 2014. Demonstration of lumpy skin disease virus infection in Amblyomma hebraeum and Rhipicephalus appendiculatus ticks using immunohistochemistry. Ticks Tick Borne Dis, 5(2): 113-120, doi: 10.1016/ j.ttbdis.2013.09.010

MacDonald RAS, 1931. Pseudo - urticaria of cattle, North Rhodesia Department of Animal Health, Annual Report 1930, pp20-21

OIE, 2008. Lumpy Skin Disease (Neethling, Knopvelsiekte): A technical Report. The Centre for Food Security and Public Health, Iowa State University

OIE, 2010. OIE Manual of Diagnostic Tests and Vaccines for Terrestrial Animals. Lumpy skin disease, pp768-778

OIE, 2016. Terrestrial Manual: Lumpy skin disease. Chapter 2.4.13

Salib FA and Osman AH, 2011. Incidence of lumpy skin disease among Egyptian cattle in Giza Governorate, Egypt. Vet World, 4(4): 162-167
Sarma DK, 2009. A textbook of Veterinary Virology and Viral diseases, $2^{\text {nd }}$ edn., Kalyani publishers, New Delhi, India

Shen Y, Shephard E, Douglass N, Johnston N, Adams C et al., 2011. A novel candidate HIV vaccine vector based on the replication deficient capripoxvirus, lumpy skin disease virus (LSDV). Virol J, 8: 265, doi: 10.1186/1743422X-8-265

Stram Y, Kuznetzova L, Friedgut O, Gelman B, Yadin $\mathrm{H}$ et al., 2008. The use of lumpy skin disease virus genome termini for detection and phylogenetic analysis. J Virol Methods, 151(2): 225-229, doi: 10.1016/j.jviromet. 2008.05.003. Epub 2008 Jun 25

Sudhakar SB, Mishra N, Kalaiyarasu S, Jhade SK, Hemadri D et al., 2020. Lumpy skin disease (LSD) outbreaks in cattle in Odisha state, India in August 2019: epidemiology features and molecular studies. Transbound Emerg Dis, doi: 10.1111/tbed.13579

Tageldin MH, Wallace DB, Gerdes GH, Putterill JF, Greyling RR et al., 2014. Lumpy skin disease of cattle: an emerging problem in the Sultanate of Oman. Trop Anim Health Prod, 46: 241-246, doi: $10.1007 / \mathrm{s} 11250-013-0483-3$

Tuppurainen E, Alexandrov T and Beltrán-Alcrudo D, 2017. Lumpy skin disease field manual $-\mathrm{A}$ manual for veterinarians. FAO Animal Production and Health Manual No. 20. Rome. Food and Agriculture Organization of the United Nations (FAO)

Tuppuraine ES, Venter EH and Coetzer JA, 2005. The detection of lumpy skin disease virus in samples of experimentally infected cattle using different diagnostic techniques. Onderstepoort J Vet Res, 72: 153-164, doi: 10.4102/ojvr.v72i2.213

Vorster JH and Mapham PH, 2008. Pathology of lumpy skin disease. Livest hlth Prod Rev, 1: 16-21

Young E, Basson PA and Weiss K, 1968. Experimental infection of the giraffe, impala and the Cape buffalo with lumpy skin disease virus. Onderstepoort J Vet Res, 37: 79-86 